\title{
Interfaces between bacterial and eukaryotic "neuroecology"
}

Peter D. Steinberg ${ }^{1,3,}$, Scott A. Rice ${ }^{2}$, Alexandra Campbell ${ }^{1,3}$, Diane McDougald ${ }^{2,3}$, Tilmann Harder ${ }^{1,3}$

${ }^{1}$ Centre for Marine Bio-Innovation and School of Biological, Earth and Environmental Science, University of New South Wales, Sydney, NSW, Australia, 2052

${ }^{2}$ Centre for Marine Bio-Innovation and School of Biotechnology and Biomolecular Sciences, University of New South Wales, Sydney, NSW, Australia, 2052

${ }^{3}$ Sydney Institute of Marine Science, 2 Chowder Bay Rd., Mosman NSW, Australia 2088

*p.steinberg@unsw.edu.au 


\section{Synopsis}

The sensory capacity of bacteria and macroalgae (seaweeds) is limited with respect to many modalities (visual, auditory) common in "higher" organisms such as animals. Thus we might expect that other modalities, such as chemical signalling and sensing, would play particularly important roles in their sensory ecology. Here we discuss two examples of chemical signalling in bacteria and seaweeds; i) the role of chemical defenses and Quorum Sensing (QS) regulatory systems in bacterial colonisation and infection of the red alga Delisea pulchra, and its ecological consequences, and; ii) nitric oxide (NO) regulated dispersal and differentiation in bacterial biofilms. Consistent with the goals of neuroecology, in both cases we investigate the links between specific signal mediated molecular mechanisms, and ecological outcomes, for populations or communities of bacteria or seaweeds. We conclude by suggesting that because of the fundamental role played by chemical signalling in bacteria, bacterial systems either by themselves or in interactions with other organisms have much to offer for understanding general issues in neuroecology. Thus further integration of microbiology and eukaryote biology would seem warranted, and is likely to prove illuminating. 


\section{Introduction}

Sensory signals have effects on organisms at all levels of the biological hierarchy, ranging from the molecular details of cellular signal transduction to ecosystem level effects such as the cascading effects of DMS through multiple trophic levels in the ocean (Nevitt 2008). An important goal of neuroecology - or, more broadly, sensory ecology - is to understand how (or if) signal-mediated physiological and molecular mechanisms translate into effects at the ecological levels of populations, communities and ecosystems, and vice versa. This goal reflects a long standing issue in biology, namely, Do effects at one end of the biological hierarchy (molecules, genes, cells) result in predictable or consistent effects at higher levels such as communities or ecosystems (e.g., (Whitham et al. 2006, Kraiser et al. 2011), the HERMES project http://www.esd.ornl.gov/PGG/HERMES/index.html). A key to this question is the term "predictable" as it is not surprising that molecular and cellular processes in general translate into ecological outcomes. Indeed, as all organisms ultimately function via molecular processes the relationship is inevitable, if not tautological. However, the question of whether signal mediated processes at the molecular level have predictable, emergent effects at higher ecological levels is a more interesting one, and one which is by no means resolved in any general sense.

This paper explores these issues for the interaction between bacteria and seaweeds and for bacterial biofilms. Both groups of organisms are "brainless" and "nerveless", and thus fit poorly into strict definitions of neuroecology. However, chemical mediation of interactions at many levels plays a critical role for bacteria and seaweeds. The importance of sensory ecology (Amsler and Fairhead 2005) and chemical ecology (Hay 2009) are well established for seaweeds, and the signal mediated bacterial process known as quorum sensing (QS) has been one of the most active areas of research in environmental microbiology over the last 15 years (Winans and Bassler 2002). Among other effects, QS often plays a critical role in the interaction between bacteria and higher organisms, including as a regulator of virulence in pathogens.

Bacteria would seem to be a particularly useful group of organisms in which to explore signal mediated interfaces between molecular and ecological events. 
Indeed, to many microbiologists, the question, "Do molecular events translate into ecological phenomena?" has little meaning, as they are viewed as fundamentally intertwined. And certainly the link between molecular mechanisms and ecological outcomes is well described for many microbial processes, such as the genetic and regulatory pathways underlying the nitrogen and carbon cycles or many of the other fundamental transformations of matter on the planet.

A second goal of this paper is, in the context of sensory ecology, to explore the extent of congruence between the ecology of bacteria and higher organisms, and to ask, "How can the sensory ecology of bacteria inform that of eukaryotes, and vice versa?" Unfortunately, microbial ecology and the ecology of plants and animals have for most of their respective histories progressed along separate paths, decoupling studies of the ecology of the major groups of organisms on the planet. The two fields have historically taken different approaches to ecology, with environmental microbiology being strongly empirically and methodologically driven and eukaryotic ecology richer in overall concepts, modelling and theory. In the last few years, particularly as modern sequencing methods and genomics have come to the fore, there has been the beginnings of a merging of these two fields, with studies of diversity theory and community "assembly" (Sloan et al. 2006, Sloan et al. 2007, Burke et al. 2011), keystone predation (Peterson et al. 2008), effects of spatial heterogeneity (Boles et al. 2004, Costerton 2004), and landscape ecology (Singer et al. 2006) in microbial systems. But this integration is still in its infancy. Thus we have little idea (for example) whether most of the ecological theories generated from eukaryotic ecology apply to the microbial world, the greatest source of biodiversity on the planet (Pedros-Alio 2006).

Below we develop these themes in the context of two systems, i) chemical mediation of bacterial disease in seaweeds, and ii) dispersal, variation and diversity in bacterial biofilms, and also draw briefly on other examples of molecular/ecological linkages in these systems. We suggest that a fuller integration of environmental microbiology and eukaryotic ecology is overdue, in the area of sensory ecology and other ecological sub-disciplines. Such integration is no longer hindered by methodological constraints, and both sides stand to benefit enormously by incorporating such "macro-micro" interactions into experimental hypotheses and investigations. 


\section{Disease, environmental change, quorum sensing and seaweed/bacterial interactions}

An obvious place in which to look for integrating the sensory ecology of eukaryotes and microbes is in interactions between the two, as occurs in hostpathogen interactions. The physical manifestation of disease typically results in observable, macroscopic changes in the host (i.e. the physical manifestation of a disease), and these can have important ecological consequences which can include the disappearance of entire ecosystems over large spatial scales (e.g., seagrass wasting disease; (Robblee et al. 1991, Short and Neckles 1999). The effects of diseases in natural systems is very topical, given that the frequency and severity of disease appears to be on the increase, and is linked to environmental changes (Lafferty et al. 2004, Harvell et al. 2009, Harvell and Hewson 2010), particularly those from global warming (IPCC 2007) and urbanisation (e.g. (Airoldi and Beck 2007). The effects of the environment on disease are likely to be complex, with potential changes to hosts, pathogens and the way in which signals mediate the interactions between them. In order to more fully understand the effects of environmental change on seaweed/bacterial interactions and disease, we need to gain a better understanding of the molecular cross-talk that occurs between these hosts and their pathogens.

2.1 Signals and host pathogen interactions. Broadly, both endogenous and exogenous chemical signals play critical roles in disease progression and host responses. For a pathogen to infect a host, it must first recognise and attach itself to the host, invade target tissues, then infect and multiply within host cells. These phenomena are best known for diseases of humans or other vertebrates and in humans each of these steps is typically signal-mediated and at each step, signal-mediated host defenses try to stop the infection, e.g., the chemokine-mediated production of leukocytes and specific antibodies. Environmental factors broadly affect these interactions, and as an example temperature often plays a critical role in modulating disease. This can occur through either temperature regulated virulence, e.g., most Shigella strains are innocuous at $30^{\circ} \mathrm{C}$ but become virulent at $37^{\circ} \mathrm{C}$ (Maurelli and Sansonetti 1988), or through modulation of host defences such as through an increase in host stress (e.g. in frogs ', (Raffel et al. 2006). The effects of increased temperatures on expression of 
virulence genes are particularly widespread, occurring in a broad range of bacterial pathogens (Konkel and Tilly 2000, Klinkert and Narberhaus 2009).

Signal mediated infection and defense in diseases of terrestrial plants are also well known, and disease can have widespread population, community and ecosystem effects through the death of habitat forming trees and other plants (Gibbs 1978, Brasier 1986, Robblee et al. 1991, Short and Neckles 1999). When pathogens attack plants, elicitor molecules released by damaged host cells and/or invading pathogens induce rapid, local responses from the plant (Nair 1993), such as the oxidative burst (Lamb and Dixon 1997). During this 'hypersensitive response', reactive oxygen species cause cell and tissue necrosis in affected areas, thus sacrificing parts of the plant and containing the infection within (Feys and Parker 2000). Such localised defences are often followed by the production of phenolic signalling molecules (e.g. salicyclic acid), resulting in a state of heightened defence throughout the plant known as systemic acquired resistance. Temperature again plays an important role in mediating plant-pathogen interactions, such as through its effects on chemical defences (reviewed by (Bidart-Bouzat and Imeh-Nathanie 2008).

2.2 Seaweeds, diseases and signaling. Marine organisms are persistently exposed to high densities of potentially pathogenic microorganisms in seawater (Reinheimer 1992) and water-borne diseases tend to be more severe than others (Ewald 1994). However, outside of the context of mariculture, the causal agents or almost any other details of infection of seaweeds are relatively unknown (exceptions include (Correa et al. 1994, Littler and Littler 1995, Campbell et al. 2011a, Case et al. 2011). As the dominant habitat-forming organisms on temperate rocky reefs, understanding the mechanisms and impacts of disease on seaweeds in natural communities is crucial. Moreover, given the importance of signal mediation in terrestrial plants (above) we may expect signals to be similarly important in modulating the effects of disease.

To date, the best known example of signal mediated host-pathogen interactions is the oxidative burst response in seaweeds (Lamb and Dixon 1997). This receptor-mediated immunity response against pathogenic or cell-wall degrading microbes, fungi and microalgae, results in the production of reactive oxygen species (ROS) such as superoxide ions $\left(\mathrm{O}_{2}-\bullet\right)$, hydrogen peroxide $\left(\mathrm{H}_{2} \mathrm{O}_{2}\right)$, or hydroxyl 
radicals $(\mathrm{OH} \bullet)($ Delledonne et al. 2001, Torres and Dangl 2005) . It is a widespread inducible mode of defense in all vascular plants and, as the name suggests, quickly mitigates pathogens and their toxins due to the strong oxidising potential of ROS.

While so far no macroalgal receptor has been isolated or characterized for a particular pathogen, there is clear evidence from in-vitro assays that microbe associated or induced molecular patterns (MAMPS, MIMPS) (Mackey and McFall 2006) transcribe this information. These molecular patterns are either comprised of the major components of the outer cell envelopes of gram-negative and -positive bacteria (lipopolysaccharides and lipoteichoic acids) (Meyer et al. 2001, Erbs and Newman 2003, Kuepper et al. 2006), or breakdown products of macroalgal cell walls due to enzymatic (glucohydrolytic) activities of pathogens (Weinberger et al. 1994, Kuepper et al. 2001, Weinberger et al. 2005, Kuepper et al. 2006). After the perception of MAMPs or MIMPs, the oxidative burst response is mediated by the flavoenzyme NADPH-oxidase located in the plasma membrane of the algal host (Weinberger et al. 2005). Parallel to the activation of NADPH-oxidase, key enzymes and hormones involved in the biosynthesis of algal defense compounds have been observed in macroalgae (Bouarab et al. 2004). These signalling cascades result for example in the biosynthesis of phlorotannins (a group of polyphenolic defense compounds) (Arnold et al. 2001, Pohnert 2004).

2.3 Delisea pulchra, bleaching and quorum sensing (QS). Delisea pulchra is a chemically defended seaweed common on subtidal reefs from temperate Australia to Antarctica. It produces secondary metabolites known as halogenated furanones (deNys et al. 1993) that inhibit mammalian (Hentzer et al. 2003b) and plant (Manefield et al. 2001) bacterial pathogens, in part through specific inhibition of their cell-to-cell QS (see below) signaling systems.

Natural populations of $D$. pulchra on the coast of New South Wales, Australia undergo a seasonal bleaching phenomenon, which in affected individuals is characterised by a reduction in concentrations of photosynthetic pigments and halogenated furanones. Bleaching is more common in summer when water temperatures are high (Campbell et al. 2011a) but is not well correlated with increases in Photosynthetically Active Radiation (PAR) or UV irradiation. Levels of 
halogenated furanones are negatively correlated with the incidence of bleaching in $D$. pulchra. The production of these secondary metabolites is metabolically costly (Dworjanyn et al. 2006) and thus exposure to 'stressful' conditions (e.g. high temperatures) may depress furanones and increase the susceptibility of D. pulchra to bacterial pathogens.

We tested the proposed role of furanones in bleaching of the thallus in the first direct in situ demonstration of the effects of algal secondary metabolites on marine bacteria, in which bleaching was induced in D. pulchra by experimentally inhibiting the production of furanones and then exposing undefended algae in the field to ambient seawater microbes (Campbell et al. 2011a). Levels of bleaching in chemically undefended thalli were much higher than in defended control algae, which only had low levels of bleaching. A similar bleaching response was observed in laboratory experiments in which undefended algae were exposed to a putative bacterial pathogen (Ruegeria sp. R11; (Case et al. 2011). In these experiments, bleaching was more common and severe when temperatures are also elevated (Campbell et al. 2011a).

Bleaching of D. pulchra is also associated with shifts in microbial communities attached to algal surfaces - a common occurrence in the progression of marine diseases (e.g. (Frias-Lopez et al. 2002, Pantos et al. 2003). In D. pulchra, microbial shifts occur prior to visible bleaching but after detectable decreases in furanone concentrations (Campbell et al. 2011b).

Bleaching of D. pulchra has significant individual, population and food web consequences. Bleached individuals are smaller than healthy conspecifics, suggesting that they grow more slowly and/or lose biomass as a result of bleaching. Furthermore, bleached individuals are significantly less fecund than healthy conspecifcs (roughly by a factor of 10), with fewer fertile tetrasporangia per gram and fewer fertile tips than healthy algae (Campbell 2011). Bleaching also alters this habitat-forming seaweeds' interactions with other trophic levels: algae that bleach are more likely to be used as habitat by locally-abundant herbivores and are also more likely to be consumed by these herbivores (Campbell 2011).

This host-pathogen system is likely to be much more general $D$. pulchra or the one bacterium (R11) we demonstrated to cause bleaching. Similar bleaching is 
observed in other species of seaweeds (Campbell, pers. observ.), and (Case et al. 2011) found that a second bacterium (PR1B), isolated from an alga from the U.S.A., could also infect and bleach D. pulchra cultured in Sydney, Australia. Furthermore, seven phylogenetically diverse bacterial strains isolated from bleached D. pulchra thalli were able to infect and bleach undefended algae (Fernandez 2011). Importantly, genomic evidence indicates that these seven pathogens have QS regulatory systems (Fernandez 2011), and evidence that putative pathogens of $D$. pulchra have QS genes provides a potentially strong link between molecular mechanisms and ecological outcomes for the Delisea - bacterial disease system.

QS is a regulatory system used by a range of bacteria to control the expression of genes at the colony, population or even community level (through cross talk among species). The system is based on the enzymatic production and release of small signal molecules, acylated homoserine lactones (AHLs), by an enzyme in the LuxI family of homologues (Fuqua and Greenberg 2002, Winans and Bassler 2002). When the extracellular AHLs reach a certain threshold concentration they bind to the cognate receptor, LuxR or its related homologues. This receptor protein also functions as a transcription factor and can induce the expression of target genes (Fuqua and Greenberg 2002, Winans and Bassler 2002). By coupling an extracellular signal with gene expression, the bacteria are able to control gene expression in such a way that the majority of the population express the same phenotype simultaneously. The range of effects of bacterial QS are incredibly broad, including production of exoenzymes for the scavenging of nutrients, mediating defensive responses, regulating symbiosis phenotypes, and community association, e.g. biofilm formation (Rice et al. 2007). Importantly in this context, QS also plays a crucial role in regulating bacterial traits associated with infection, virulence factor expression and biofilm formation in a wide variety of plant, animal and human diseases and examples of such bacteria include Vibrio harveyi (prawns) (Manefield et al. 2000), Vibrio anguillarum (fish) (Rasch et al. 2004), Pseudomonas aeruginosa (plants, insects and humans) (Amsler and Fairhead 2005), Burkholderia spp. (plants and humans) (Burke et al. 2011), Erwinia carotovora (plants) (Mukherjee et al. 1997), and Serratia marcescens (humans) (Eberl et al. 1996).

Given the widespread role of QS in pathogenicity and disease, a number of authors have proposed that potential hosts should evolve to produce compounds that 
specifically interfere with QS in order to defend themselves from colonisation and infection by bacteria (Bauer and Teplitski 2001, Hentzer et al. 2003b, McDougald et al. 2007). Indeed, this is the strategy used by D. pulchra to defend itself from pathogenic bacteria, where the alga produces halogenated furanones (reviewed by de Nys et al. 2006), which are structurally similar to the bacterial QS signal molecules, acylated homoserine lactones (AHLs) (Manefield et al. 1999). These furanones specifically interfere with the binding of the QS molecules to the bacterial receptor (Manefield et al. 1999), and thus inhibiting the expression of QS regulated genes (e.g. biofilm formation (Maximilien et al. 1998) and virulence (Manefield et al. 2001)).

Not surprisingly, QS is common in the marine environment. A number of free living and invertebrate-associated marine bacteria from $\alpha$ - and $\gamma$-Proteobacteria groups produce AHLs (Sloan et al. 2007). For example, bacteria associated with a range of sponge species have been shown to produce AHLs (Gibbs 1978, Robblee et al. 1991) as have marine biofilms (Brasier 1986). Likewise the inhibition of AHLmediated QS appears to be common in the marine environment. In a study examining 284 extracts of sponges, corals and algae, 23\% had AHL-inhibitory activity (BidartBouzat and Imeh-Nathanie 2008). These data indicate that the co-evolution of bacteria and higher eukaryotes has likely resulted in numerous examples of QS and QS-antagonism in these organisms.

Examples of eukaryote hosts that, like D. pulchra, produce metabolites that interfere with bacterial QS are not limited to the marine environment, and examples have been isolated from food, fungal, plant and herbal sources (Rasmussen et al. 2005, Bjarnsholt and Givskov 2007). In particular, extracts from garlic have anti-QS activity and have been shown to reduce virulence in a nematode infection model (Rasmussen et al. 2005). The roots of Medicago truncatula multiple QS-active compounds (Teplitski et al. 2000). Even fungi, which may be commensuals on plants, have been shown to produce QS inhibiting compounds (Rasmussen et al. 2005). Thus it is clear that QS antagonists have evolved in a broad range of hosts that interact in nature with bacteria.

The importance of QS systems in bacterial disease and virulence generally and the increasing genomic or chemical observations of QS systems or QS antagonists in 
marine organisms suggest that our specific findings for the Delisea pulchra/bacteria system (Fig. 1) will be common for many systems in the marine environment. That is, signal based QS systems are likely to be a crucial way in which molecular mechanisms can be translated via virulence disease phenotypes into ecological effects at the host population level and beyond into interactions with other trophic levels and ultimately throughout an ecosystem. This suggests, that as for D. pulchra, QS antagonists in hosts should be common (Dobretsov et al 2009). The dependence of these interactions generally on environmental factors such as increasing temperature is less clear. However, to the extent that stress diminishes host defenses, as for furanones and $D$. pulchra, this should facilitate an increase in the impacts of disease. In this context, an interesting area for further research is to explore the temperature dependency of QS regulated virulence.

\section{Development, dispersal and nitric oxide signaling in bacterial biofilms}

Most bacteria in the environment are now thought to occur in biofilms, which are surface aggregations of bacterial cells embedded in an extracellular matrix. Their biology is typically quite distinct from that of planktonic cells (see volumes by (Kjelleberg and Givskov 2007) for reviews of bacterial biofilm biology and ecology). Biofilms are analogous to multicellular, eukaryotic organisms in a number of ways, and thus are suitable test systems for exploring the interface between eukaryotic and prokaryotic ecology. Biofilms are "multicellular" a number of senses, where they represent collections of cells which function in relationship to one another, based on signal mediated communication between these cells (Hentzer et al. 2003a, Landini et al. 2010).

3.1 Biofilm life cycles. Biofilms are essentially sessile, and single species biofilms are clonal, derived from the asexual replication of cells. Thus they are modular in the same sense as clonal marine invertebrates such as corals, bryozoans, colonial ascidians and many others. One particularly striking analogy between clonal invertebrates and biofilms is the presence of a predictable developmental program in which individual cells or larvae colonise a surface, develop into a sessile colony, and then produce differentiated, dispersive propagules which then colonise new surfaces, 
completing the life cycle. These "life cycle" stages occur with predictable changes morphology, gene expression and physiology over time. Such life histories are well known for marine invertebrates, but only in recent years has it become evident that they are common in biofilms as well (Fig 2). As is the case for marine invertebrates, the dispersal phase of the biofilm life cycle generates propagules which can disperse away from the maternal colony and colonise new habitats. Importantly, these dispersers are also associated with the generation of variation by the colony (Boles et al. 2004, Kirov et al. 2007, Koh et al. 2007), in the same way that sexually produced, dispersive larvae are a source of variation for an otherwise asexually replicating coral colony.

These dispersers are typically differentiated, and are produced through a process that is distinct from the passive release of cells due to detachment or sloughing that can occur as a biofilm grows into the water column, and is exposed to higher sheer forces as it escapes the boundary layer effects. Thus, the process of active dispersal is analogous to the release of motile dispersal propagules from clonal eukaryotes. The production of differentiated dispersal cells from the biofilm colony is a regulated process, responding to environmental cues and subject to control by endogenous signalling pathways. Environmental cues which initiate the dispersal and differentiation process may be external to the biofilm, e.g., the presence of a predator or toxic compounds, or be internal cues such as nutrient limitation or the buildup of reactive oxygen species within the biofilm (Sauer et al. 2004, Thormann et al. 2005, Barraud et al. 2006, Schleheck et al. 2009). Following exposure to cues, it appears that dispersal is then regulated via molecular mechanisms that are comprised generally of perception of the cue or stress by a receptor followed by an intracellular signal cascade that results in upregulating those genes required for a bacterium to degrade the binding EPS (extracellular polymeric substances) material which gives the biofilm its coherency, to become motile and to swim away from the colony (Sloan et al. 2006, Landini et al. 2010).

3.2 Nitric oxide and dispersal from biofilms. One signaling molecule that plays a key role in initiating dispersal from biofilms is nitric oxide (NO) (Barraud et al. 2006). NO plays an important role in the regulation of a wide range of physiological processes in plants and animals, but the role of NO signalling in controlling the 
biofilm lifecycle is a recent discovery. Biofilm development results in cell death of a subpopulation of cells at the time of dispersal and this autocidal activity is genetically regulated as opposed to cell death due to a lack of nutrients and/or accumulation of toxic waste products. One consequence of reduced oxygen concentrations in the interior of the biofilm is the induction of the denitrification pathway. Nitrate reductase, encoded by nirS, generates NO as a by-product and the accumulation of NO at low levels in the biofilms induces dispersal. Exposure of bacteria to NO leads to changes in the concentration of the intra-cellular signalling nucleotide, cyclic-diGMP (Barraud et al. 2009). The c-di-GMP concentrations are controlled by the activity of proteins that either make guanylate cyclases, or degrade, phosphodiesterases, c-di-GMP, and these are presumed to be activated by the NO sensor or subsequent signal cascade. This is again similar to the function of NO in mammalian systems, where NO alters the intracellular pool of cyclicGMP (cGMP) to alter gene expression and activity. It now seems clear that NO acts as a signal to bacteria on the interior of the biofilm to disperse which is associated with the generation of dispersal variants and the subsequent colonisation of new niches.

It is particularly interesting to note that NO has been linked to a pattern of cell death that is reminiscent of the of programmed cell death in plants that occurs as a consequence of the hypersensitive response when exposed to pathogens (Clarke et al. 2000, Neill et al. 2002, Neill et al. 2003). The effects of NO on biofilms are also concentration dependent. At low NO concentrations, biofilms are dispersed whereas when NO concentrations are high, presumable at toxic levels, biofilm formation is enhanced. A similar biphasic response to the concentration of NO has also been reported in plants, as tomato, lettuce and pea plants exhibit stimulation of growth at low NO concentrations and inhibition of growth at high concentrations (Hufton et al. 1996, Leshem and Haramaty 1996). Thus, there are clearly conserved signalling pathways shared by both bacteria and eukaryotes that affect multicellular activities and signalling pathways.

3.3 Consequences of signal mediated development and dispersal in biofilms. The generation of differentiated dispersal cells from biofilms via the NO signaling cascade has a number of ecological consequences, which are associated with the development of genetic variation at the time these dispersers are generated. This association of 
variation with dispersers appears common to the production of biofilm dispersers, whether induced by the NO pathway or other mechanisms e.g., bacteriophage mediated dispersal in Pseudomonas aeruginosa (Rice et al. 2009), and again is analogous to the sexually generated variation which occurs via the production of dispersive gametes or larvae by marine invertebrates. These variants differ in a number of key traits associated with colonisation or subsequent biofilm growth. For example, variation in dispersal cells harvested downstream from biofilms of Serratia marcescens grown in flow cells were first detected when they were replated, and grew to form small colony variants (SCVs) or mucoid colony types, which were distinct form the parental biofilm (Koh et al. 2007). These cells would have undergone dozens of generations to form these colonies, and thus this variation in colony morphology among dispersal cells is heritable. Remarkably, the morphological variation in these colony types is due to single nucleotide changes in one gene, etk, that regulates EPS production (Koh et al., in review).

Subsequent testing of random dispersal isolates indicates that they also differ in other key phenotypic traits such as motility, biofilm formation, QS responses, virulence factor expression and nutrient utilisation (Deziel et al. 2001, Drenkard and Ausubel 2002, Pedros-Alio 2006). Such variation is consistent with evolutionary models for dispersal in marine invertebrates or other eukaryotes in which the advantage of producing variable, dispersive propagules is the increased capacity to colonise habitats which are distinct from the parental environment and spatially variable or temporally unpredictable habitats (Bowler and Benton 2005, Ronce 2007). Thus the production of variant dispersive cells initiated by NO or other dispersal pathways, from otherwise largely sessile biofilms, should enhance the persistence of these biofilms at the broader (meta)population level

The generation of variants also enhances performance of biofilms with respect to what is generally considered to be one of the key mortality factors faced by bacteria, grazing by protozoans. This stems form the observation that when variable dispersal cells are generated, many of these cells do not in fact escape the biofilm but persist within it. In some species of bacteria, the proportion of variants in the sessile biofilm relative to wild type (WT) cells can be as high as $50 \%$. In a series of experiments (Koh et al. in review), we exposed monotypic and multivariate biofilms to grazing by the protozoan grazer Acanthamoeba castellani. Monotypic biofilms 
included WT colonies and biofilms derived from each variant. Multivariant bioiflms consisted of a mixture of four variants, either with or without WT cells. These biofilms were exposed to grazing for 12 days, and compared to controls of each type in which grazers were absent. All types of variants persisted in the multivariant biofilms for the duration of the experiment.

We (Koh et al., in review) found that multivariant biofilms (with or without the WT included) were significantly (2-4 fold) more resistant to grazing than WT biofilms or biofilms comprised of individual variants when grown separately. Using the analytical techniques of Hector and Loreau (Loreau and Hector 2001), we showed that this effect was not simply due to one very resistant variant, but that there was a strong "complementarity" effect. That is, there was an emergent effect of variant diversity on resistance to predation. This is consistent with recent observations on the effects of genotypic diversity on the performance or functioning of populations (Whitham et al. 2006). Koh et al. (in review) have shown that these concepts can be applied to genetic diversity in biofilms. Indeed, they have arguably extended this work by quantifying the amount of genetic diversity necessary for significant emergent ecological effects, which in the case of $S$. marcescens is minimal; Single Nucleotide Polymorphisms (SNPs) at one locus.

To summarise these studies of biofilm populations, fine scale molecular events, mediated by specific cues such as NO, translate to affect significant ecological phenomena involving a) dispersal and potentially metapopulation dynamics, and b) resistance to grazing. Our model for how these different levels of phenomena interconnect is shown in Fig 3.

\section{Conclusions}

A primary goal of this paper was to understand whether neuroecology, or more broadly sensory ecology, is a useful approach to understanding chemically mediated interactions among bacteria or between bacteria and their seaweed hosts. Implicit in this is the hypothesis that there are strong mechanistic links between particular, signal based, genetic or molecular mechanisms and emergent ecological phenomena at the population, community or ecosystem level (e.g., genes to ecosystems; Whitham et al, 2006). For the quorum sensing based interactions that seem to underlie at least some of the pathogenic interactions between D. pulchra and 
marine bacteria, this would seem to be the case. Quorum sensing is a remarkably widespread phenomenon among bacterial populations and communities, and we and others (Bauer and Teplitski 2001, Manefield et al. 2001, Hentzer et al. 2003a, Hentzer et al. 2003b, Bjarnsholt and Givskov 2007, McDougald et al. 2007, Rice et al. 2007) have argued that one primary role for QS is to regulate interactions between bacteria and higher organisms generally, including in the context of disease. In the case of Delisea pulchra, this signal based mechanism is both affected by the broader environment (temperature, possibly UV radiation), via decreases in host QS antagonists and potentially increased virulence of pathogens, and has ecological consequences to the seaweeds at the individual (tissue damage), population (fecundity) and broader community (interactions with herbivores) level.

The second example focused on molecular - ecological linkages in the microecological world of bacterial biofilms. Here, a common biological signal nitric oxide - induces differentiation, variation and dispersal in biofilms. This signal based mechanism we suggest affects subsequent colonisation of habitats (via the generation of variable dispersers), and we have experimentally showed that this variation has consequences for resistance to grazing in biofilms. Remarkably, the molecular mechanism underlying these effects are single nucleotide polymorphisms at one locus (the etk gene), showing that significant ecological effects of diversity can result form minimal genetic change. Like QS systems, generation of variation associated with dispersal in biofilms appears widespread among bacteria (though the signals are not always NO). Thus the link between molecular mechanisms and ecological outcomes also appears strong for these phenomena.

Both these examples raise the issue of the extent of congruence between the sensory ecology of bacteria and higher organisms, and whether the sensory ecology of bacteria can inform that of eukaryotes, and vice versa. Unfortunately, microbial ecology and the ecology of plants and animals generally have for most of their respective histories progressed along separate paths, decoupling studies of the ecology of the major groups of organisms on the planet. The two fields have historically taken different approaches to ecology, with environmental microbiology being strongly empirically and methodologically driven and eukaryotic ecology richer in overall concepts, modelling and theory. In the last few years, particularly as modern sequencing methods and genomics have come to the fore, there has been the 
beginnings of a merging of these two fields, with studies of diversity theory and community "assembly" (Sloan et al. 2006, Sloan et al. 2007, Burke et al. 2011), keystone predation (Peterson et al. 2008), effects of spatial heterogeneity (Boles et al. 2004, Costerton 2004), and landscape ecology (Singer et al. 2006) in microbial systems. But this integration is still in its infancy and little explored in the context of sensory ecology. Based on the examples explored in this paper, and the widespread use of signal based systems in the interactions between bacteria and bacteria and higher organisms, we suggest such an integration would be beneficial to both fields.

\section{Acknowledgements:}

The authors gratefully acknowledge the support of NSF and the SICB, and the generosity and patience of the symposium organisers, Chuck Derby and Dick Zimmer. Much of the work described here was supported by the Australian Research Council and National Health and Medical Research Council. 


\section{References:}

Airoldi, L. and M. Beck. 2007. Loss, status and trends for coastal marine habitats of Europe. Pages 345-405 Oceanography and Marine Biology. CRC PressTaylor \& Francis Group, Boca Raton.

Amsler, C. D. and V. A. Fairhead. 2005. Defensive and sensory chemical ecology of brown algae. Advances in Botanical Research 43:1-91.

Arnold, T. M., N. M. Targett, C. E. Tanner, W. I. Hatch, and K. E. Ferrari. 2001. Evidence for methyl-jasmonate induced phlorotannin production in Fucus vesiculosus (Phaeophyceae). J. Phycol. 37:1026-1029.

Barraud, N., D. J. Hassett, S.-H. Hwang, S. A. Rice, S. Kjelleberg, and J. S. Webb. 2006. Involvement of nitric oxide in biofilm dispersal of Pseudomonas aeruginosa. J. Bacteriol. 188:7344-7353.

Barraud, N., D. Schleheck, J. Klebensberger, J. Webb, D. Hassett, S. Rice, and S. Kjelleberg. 2009. Nitric oxide signaling in Pseudomonas aeruginosa biofilms mediates phosphodiesterase activity, decreased cyclic di-GMP levels, and enhanced dispersal. J. Bacteriol. 191:7333-7342.

Bauer, W. D. and M. Teplitski. 2001. Can plants manipulate bacterial quorum sensing? Aust. J. Plant Physiol. 28:913-921.

Bidart-Bouzat, M. G. and A. Imeh-Nathanie. 2008. Global change effects on plant chemical defenses against insect herbivores. Journal of Integrative Plant Biology 50:1339-1354.

Bjarnsholt, T. and M. Givskov. 2007. The role of quorum sensing in the pathogenicity of the cunning aggressor Pseudomonas aeruginosa. 387:409-414.

Boles, B. R., M. Thoendel, and P. K. Singh. 2004. Self-generated diversity produces "insurance effects" in biofilm communities. Proceedings of the National Academy of Sciences of the United States of America 101:16630-16635.

Bouarab, K., F. Adas, E. Gaquerel, B. Kloareg, J.-P. Salaun, and P. Potin. 2004. The innate immunity of a marine red alga involves oxylipins from both the eicosanoid and octadecanoid pathways. Plant Physiol. 135:1838-1848.

Bowler, D. E. and T. G. Benton. 2005. Causes and cosequences of animal dispersal strategies. Biol. Rev. 80:205-225.

Brasier, C. M. 1986. The population biology of Dutch elm disease: its principal features and some implications for other host-pathogen systems. Advances in plant pathology 5:53-118.

Burke, C., T. Thomas, M. Lewis, P. Steinberg, and S. Kjelleberg. 2011. Composition, uniqueness and variability of the epiphytic bacterial community of the green alga Ulva australis. The ISME Journal 5:590-600.

Campbell, A. H. 2011. The ecology of bacterially-mediated bleaching in a chemically defended seaweed. University of New South Wales, Sydney.

Campbell, A. H., T. Harder, S. Nielsen, S. Kjelleberg, and P. D. Steinberg. 2011 a. Climate change and disease: bleaching ofa chemically defended seaweed.

Campbell, A. H., A. Verges, T. Harder, and P. D. Steinberg. 2011b. Causes and ecological consequences of a climate-mediated disease. Aust. Zool. in press.

Case, R. J., S. R. Longford, A. H. Campbell, A. Low, N. Tujula, P. D. Steinberg, and S. Kjelleberg. 2011. Temperature induced bacterial virulence and bleaching 
disease in a chemically defended marine macroalga. Environmental Microbiology 13:529-537.

Clarke, A., R. Desikan, R. D. Hurst, J. T. Hancock, and S. J. Neill. 2000. NO way back: nitric oxide and programmed cell death in Arabidopsis thaliana suspension cultures Plant Journal 24:667-677.

Correa, J. A., V. Flores, and J. Garrido. 1994. Green patch disease in IridaeaLaminarioides (Rhodophyta) caused by Endophyton sp. (Chlorphyta). Diseases of Aquatic Organisms 19:203-213.

Costerton, B. 2004. Microbial ecology comes of age and joins the general ecology community. Proceedings of the National Academy of Sciences of the United States of America 101:16983-16984.

Delledonne, M., J. Zeier, A. Marocco, and C. Lamb. 2001. Signal interactions between nitric oxide and reactive oxygen intermediates in the plant hypersensitive disease resistance response. Proc. Natl. Acad. Sci. USA Proc. Natl. Acad. Sci. USA:13454-13459.

deNys, R., A. D. Wright, G. M. Konig, and O. Sticher. 1993. New halogenated furanones from the marine alga Delisea pulchra (cf fimbriata). Tetrahedron 49:11213-11220.

Deziel, E., Y. Comeau, and R. Villemur. 2001. Initiation of biofilm formation by Pseudomonas aeruginosa 57RP correlates with emergence of hyperpiliated and highly adherent phenotypic variants deficient in swimming, swarming, and twitching motilities. J. Bacteriol. 183:1195-1204.

Drenkard, E. and F. M. Ausubel. 2002. Pseudomonas biofilm formation and antibiotic resistance are linked to phenotypic variation. Nature 416:740-743.

Dworjanyn, S. A., J. T. Wright, N. A. Paul, R. de Nys, and P. D. Steinberg. 2006. Cost of chemical defence in the red alga Delisea pulchra. Oikos 113:13-22.

Eberl, L., M. K. Winson, C. Sternberg, G. S. A. B. Stewart, G. Christiansen, S. R. Chhabra, B. Bycroft, P. Williams, S. Molin, and M. Givskov. 1996. Involvement of $N$-acyl-L-homoserine lactone autoinducers in controlling the multicellular behaviour of Serratia liquefaciens. Mol. Microbiol. 20:127-136.

Erbs, G. and M. A. Newman. 2003. The role of lipopolysaccharides in the induction of plant defence responses. Mol. Plant Pathol. 4:421-425.

Ewald, P. W. 1994. Evolution of infectious diseases. Oxford University Press, New York.

Fernandez, N. 2011. Molecular Studies on the Role of Bacteria in a Marine Algal Disease. University of New South Wales, Sydney.

Feys, B. J. and J. E. Parker. 2000. Interplay of signaling pathways in plant disease resistance. Trends in Genetics 16:449-455.

Frias-Lopez, J., A. L. Zerkle, G. T. Bonheyo, and B. W. Fouke. 2002. Partitioning of bacterial communities between seawater and healthy, black band diseased, and dead coral surfaces. Applied and Environmental Microbiology 68:2214-2228.

Fuqua, C. and E. P. Greenberg. 2002. Listening in on bacteria: Acyl-homoserine lactone signalling. Nature 3:685-695.

Gibbs, J. N. 1978. Intercontinental epidemiology of Dutch elm disease. Annual Review of Phytopathology 16:287-307.

Harvell, C. D. and I. Hewson. 2010. Climate Change and Invertebrate Microbial Interactions. Integrative and Comparative Biology 50:E69-E69.

Harvell, D., S. Altizer, I. M. Cattadori, L. Harrington, and E. Weil. 2009. Climate change and wildlife diseases: When does the host matter the most? Ecology 90:912-920. 
Hay, M. E. 2009. Marine Chemical Ecology: Chemical Signals and Cues Structure Marine Populations, Communities, and Ecosystems. Annu. Rev. Mar. Sci. 1:193-212.

Hentzer, M., L. Eberl, J. Nielsen, and M. Givskov. 2003a. Quorum Sensing: a novel target for the treatment of biofilm infections. Drug Devel. 17:241-250.

Hentzer, M., H. Wu, J. B. Andersen, K. Riedel, T. B. Rasmussen, N. Bagge, N. Kumar, M. A. Schembri, Z. J. Song, P. Kristoffersen, M. Manefield, J. W. Costerton, S. Molin, L. Eberl, P. Steinberg, S. Kjelleberg, N. Hoiby, and M. Givskov. 2003b. Attenuation of Pseudomonas aeruginosa virulence by quorum sensing inhibitors. EMBO J. 22:3803-3815.

Hufton, C. A., R. T. Besford, and A. R. Wellburn. 1996. Effects of NO $\left(+\mathrm{NO}_{2}\right)$ pollution on growth, nitrate reductase activities and associated protein contents in glasshouse lettuce grown hydorponically in winter with $\mathrm{CO}_{2}$ enrichment. New Phytol. 133:495-501.

IPCC. 2007. Climate change 2007 : the physical science basis.in S. Solomon, D. Qin, M. Manning, Z. Chen, M. Marquis, K. B. Averyt, and H. L. Miller, editors. Contribution of Working Group I to the Fourth Assessment Report of the Intergovernmental Panel on Climate Change, Cambridge,

Kirov, S. M., J. S. Webb, C. Y. O'May, D. W. Reid, J. K. K. Woo, S. A. Rice, and S. Kjelleberg. 2007. Biofilm differentiation and dispersal in mucoid Pseudomonas aeruginosa isolates from patients with cystic fibrosis. Microbiology 153:3264-3274.

Kjelleberg, S. and M. Givskov. 2007. The Biofilm Mode of Life. Pages 5-21 in S. Kjelleberg and M. Givskov, editors. The Biofilm Mode of Life: Mechanisms and Adaptations. Horizon Bioscience, Wymondham, UK.

Klinkert, B. and F. Narberhaus. 2009. Microbial thermosensors. Cellular and Molecular Life Sciences 66:2661-2676.

Koh, K. S., K. W. Lam, M. Alhede, S. Y. Queck, M. Labbate, S. Kjelleberg, and S. A. Rice. 2007. Phenotypic diversification and adaptation of Serratia marcescens MG1 biofilm-derived morphotypes. J. Bacteriol. 189:119-130.

Konkel, M. E. and K. Tilly. 2000. Temperature-regulated expression of bacterial virulence genes. Microbes and Infection 2:157-166.

Kraiser, T., D. E. Gras, A. G. G. Gutiérrez, B. González, and R. A. Gutiérrez. 2011. A holistic view of nitrogen acquisition in plants. Journal of Experimental Botany 62:1455-1466.

Kuepper, F. C., E. Gaquerel, E.-M. Boneberg, S. Morath, J.-P. Salaun, and P. Potin. 2006. Early events in the perception of lipopolysaccharides in the brown alga Laminaria digitata include an oxidative burst and activation of fatty acid oxidation cascades. Journal of Experimental Botany 57:1991-1999.

Kuepper, F. C., B. Kloareg, J. Guern, and P. Potin. 2001. Oligoguluronates elicit an oxidative burst in the brown algal kelp. Plant Physiol. 125:278-291.

Lafferty, K. D., J. W. Porter, and S. E. Ford. 2004. Are diseases increasing in the ocean? Annual Review of Ecology Evolution and Systematics 35:31-54.

Lamb, C. and R. A. Dixon. 1997. The oxidative burst in plant disease resistance. Annual Review of Plant Physiology and Plant Molecular Biology 48:251-275.

Landini, P., D. Antoniani, J. Burgess, and R. Nijland. 2010. Molecular mechanisms of compounds affecting bacterial biofilm formation and dispersal. Appl. Microbiol. Biotechnol. 86:813-823. 
Leshem, Y. Y. and E. Haramaty. 1996. The characterization and contrasting effects of the nitric oxide free radical in vegetative stress and senescence of Pisum sativum Linn. foliage. Journal Plant Physiology 148:258-263.

Littler, M. M. and D. S. Littler. 1995. Impact of CLOD pathogen on Pacific coral reefs. Science 267:1356-1360.

Loreau, M. and A. Hector. 2001. Partitioning selection and complementarity in biodiversity experiments. Nature 412:72-76.

Mackey, D. and A. J. McFall. 2006. MAMPs and MIMPs: proposed classifications for inducers of innate immunity. Mol. Microbiol. 61:1365-1371.

Manefield, M., N. R. de, N. Kumar, R. Read, M. Givskov, P. Steinberg, and S. Kjelleberg. 1999. Evidence that halogenated furanones from Delisea pulchra inhibit acylated homoserine lactone (AHL)-mediated gene expression by displacing the AHL signal from its receptor protein. Microbiology 145:283291.

Manefield, M., L. Harris, S. A. Rice, R. De Nys, and S. Kjelleberg. 2000. Inhibition of luminescence and virulence in the black tiger prawn (Penaeus monodon) pathogen Vibrio harveyi by intercellular signal antagonists. Applied and Environmental Microbiology 66:2079-2084.

Manefield, M., M. Welch, M. Givskov, G. P. C. Salmond, and S. Kjelleberg. 2001. Halogenated furanones from the red alga, Delisea pulchra, inhibit carbapenem antibiotic synthesis and exoenzyme virulence factor production in the phytopathogen Erwinia carotovora. FEMS Microbiol. Lett. 205:131-138.

Maurelli, A. T. and P. J. Sansonetti. 1988. Identification of a chromosomal gene controlling temperature-regulated expression of Shigella virulence. Proceedings of the National Academy of Sciences of the United States of America 85:2820-2824.

Maximilien, R., R. deNys, C. Holmstrom, L. Gram, M. Givskov, K. Crass, S. Kjelleberg, and P. Steinberg. 1998. Chemical mediation of bacterial surface colonisation by secondary metabolites from the red alga Delisea pulchra. Aquatic Microb. Ecol. 15:233-246.

McDougald, D., S. A. Rice, and S. Kjelleberg. 2007. Bacterial quorum sensing and interference by naturally occurring biomimics. Anal. Bioanl. Chem. 387:445453.

Meyer, A., A. Puehler, and K. Niehaus. 2001. The lipopolysaccharides of the phytopathogen Xanthomonas campestris pv. campestris induce an oxidative burst reaction in cell cultures of Nicotiana tabacum. Planta 213:214-222.

Mukherjee, A., Y. Y. Cui, Y. Liu, and A. K. Chatterjee. 1997. Molecular characterization and expression of the Erwinia carotovora hrpN(ecc) gene, which encodes an elicitor of the hypersensitive reaction. Mol. Plant. Micro. Interact. 10:462-471.

Nair, A. S. 1993. Molecular communications during plant pathogen interactions. Current Science 65:677-679.

Neill, S. J., R. Desikan, A. Clarke, R. D. Hurst, and J. T. Hancock. 2002. Hydrogen peroxide and nitric oxide as signalling molecules in plants Journal of Experimental Botany 53:1237-1247.

Neill, S. J., R. Desikan, and J. T. Hancock. 2003. Nitric oxide signalling in plants New Phytol. 159:11-35.

Nevitt, G. A. 2008. Sensory ecology on the high seas: The odor world of the procellariiform seabirds. J. Exp. Biol. 211:1706-1713. 
Pantos, O., R. P. Cooney, M. D. A. Le Tissier, M. R. Barer, A. G. O'Donnell, and J. C. Bythell. 2003. The bacterial ecology of a plague-like disease affecting the Caribbean coral Montastrea annularis. Environmental Microbiology 5:370382.

Pedros-Alio, C. 2006. Marine microbial diversity: can it be determined? Trends Microbiol. 14:257-263.

Peterson, C. N., S. Day, B. E. Wolfe, A. M. Ellison, R. Kolter, and A. Pringle. 2008. A keystone predator controls bacterial diversity in the pitcher-plant (Sarracenia purpurea) microecosystem. Environmental Microbiology 10:2257-2266.

Pohnert, G. 2004. Chemical defense strategies of marine organisms. Top. Curr. Chem. 239:179-219.

Raffel, T. R., J. R. Rohr, J. M. Kiesecker, and P. J. Hudson. 2006. Negative effects of changing temperature on amphibian immunity under field conditions. Functional Ecology 20:819-828.

Rasch, M., C. Buch, B. Austin, W. J. Slierendrecht, K. S. Ekmann, J. L. Larsen, C. Johansen, K. Riedel, L. Eberl, M. Givskov, and L. Gram. 2004. An inhibitor of bacterial quorum sensing reduces mortalities caused by vibriosis in rainbow trout (Oncorhynchus mykiss, Walbaum). Syst. Appl. Microbiol. 27:350-359.

Rasmussen, T. B., T. Bjarnsholt, M. E. Skindersoe, M. Hentzer, P. Kristoffersen, M. Kote, J. Nielsen, L. Eberl, and M. Givskov. 2005. Screening for quorumsensing inhibitors (QSI) by use of a novel genetic system, the QSI selector. J. Bacteriol. 187:1799-1814.

Reinheimer, G. 1992. Aquatic microbiology. Wiley, New York.

Rice, S. A., D. McDougald, M. Givskov, and S. Kjelleberg. 2007. Detection and Inhibition of Bacterial Cell-Cell Communication. Pages 55-68 in F. DeLeo, editor. Bacterial Pathogenesis Methods and Protocols. Humana Press, New Jersey.

Rice, S. A., C. H. Tan, P. J. Mikkelsen, V. Kung, J. Woo, M. Tay, A. Hauser, D. McDougald, J. S. Webb, and S. Kjelleberg. 2009. The biofilm life cycle and virulence of Pseudomonas aeruginosa are dependent on a filamentous prophage. The ISME Journal 3:271-282.

Robblee, M. B., T. R. Barber, P. R. J. Carlson, M. J. Durako, J. W. Fourqurean, L. K. Muehlstein, D. Porter, L. A. Yarbro, R. T. Zieman, and a. J. C. Zieman. 1991. Mass mortality of the tropical seagrass Thalassia testudinum in Florida Bay (USA). Marine Ecology Progress Series 71:297-299.

Ronce, O. 2007. How does it feel to be like a rolling stone? Ten questions about dispersal evolution. Ann. Rev. Ecol. Syst. 38:231-253.

Sauer, K., M. C. Cullen, A. H. Rickard, L. A. H. Zeef, D. G. Davies, and P. Gilbert. 2004. Characterization of nutrient-induced dispersion in Pseudomonas aeruginosa PAO1 biofilm. J. Bacteriol. 186:7312-7326.

Schleheck, D., N. Barraud, J. Klebensberger, J. S. Webb, D. McDougald, S. A. Rice, and S. Kjelleberg. 2009. Pseudomonas aeruginosa PAO1 preferentially grows as aggregates in liquid batch cultures and disperses upon starvation. PLoS Biol. Accepted.

Short, F. T. and H. A. Neckles. 1999. The effects of global climate change on seagrasses. Aquatic Botany 63:169-196.

Singer, R. S., M. P. Ward, and G. Maldonado. 2006. Can landscape ecology untangle the complexity of antibiotic resistance? Nat. Rev. Microbiol. 4:943-952. 
Sloan, W. T., M. Lunn, S. Woodcock, I. M. Head, S. Nee, and T. P. Curtis. 2006. Quantifying the roles of immigration and chance in shaping prokaryote community structure. Environmental Microbiology 8:732-740.

Sloan, W. T., S. Woodcock, M. Lunn, I. M. Head, and T. P. Curtis. 2007. Modeling taxa-abundance distributions in microbial communities using environmental sequence data. Microbial Ecology 53:443-455.

Teplitski, M., J. B. Robinson, and W. D. Bauer. 2000. Plants secrete substances that mimic bacterial $N$-acyl homoserine lactone signal activities and affect population density-dependent behaviors in associated bacteria. Mol. Plant. Micro. Interact. 13:637-648.

Thormann, K. M., R. M. Saville, S. Shukla, and A. M. Spormann. 2005. Induction of rapid detachment in Shewanella oneidensis MR-1 biofilms. J. Bacteriol. 187:1014-1021.

Torres, M. A. and J. Dangl. 2005. Functions of the respiratory burst oxidase in biotic interactions, abiotic stress and development. Curr. Opin. Plant Biol. 8:397403.

Weinberger, F., M. Friedlander, and W. Gunkel. 1994. A bacterial facultative parasite of Gracilaria conferta. Diseases of Aquatic Organisms 18:135-141.

Weinberger, F., P. Leonardi, A. Miravalles, J. A. Correa, U. Lion, B. Kloareg, and P. Potin. 2005. Dissection of two distinct defense related responses to agar oligosaccharides in Gracilaria chilensis (Rhodophyta) and Gracilaria conferta (Rhodophyta). J. Phycol. 41:863-873.

Whitham, S. A., C. L. Yang, and M. M. Goodin. 2006. Global impact: Elucidating plant responses to viral infection. Molecular Plant-Microbe Interactions 19:1207-1215.

Winans, S. C. and B. L. Bassler. 2002. Mob psychology. J. Bacteriol. 184:873-883.

\section{Figure Legends}

Figure 1. A model for bacterial bleaching of D. pulchra, integrating both molecular mechanisms and effects at the level of individual thalli, populations and the broader community. We propose that the progression of bleaching in D. pulchra is: Under sub-optimal environmental conditions, algal chemical defences (furanones) decrease, surface-associated microbial communities begin to change in composition including infection by pathogens leading to bleaching. Bleaching has ecological consequences for this seaweed, leading at least to a decrease in fecundity and an increase in grazing. Underlying this for at least some pathogens is QS regulated virulence, which increases the ability of opportunistic pathogens to attack the algae when QS blocking furanones are depleted.

Figure 2. Lifecycles of colonial organisms. A. The lifecycle of a bacterial biofilm where i) the mature, surface associated, sessile biofilm undergoes cell death and 
hollow colony formation to ii) actively release individual, free-swimming, planktonic dispersal cells or that iii) passively shed aggregates of cells (e.g. through the action of hydrodynamic shear on the biofilm surface). Ultimately, dispersal cells iv) identify and attach to surfaces and reinitiate biofilm development though standard cell dvision.

Figure 3. Bacterial biofilm development, dispersal and variant formation. A. The biofilm development lifecycle, from left to right, proceeds from attachment to mature microcolonies at which time, signals such as nitric oxide (NO) are produced through endogenous metabolism which initiates dispersal. Dispersal culminates in cell death and hollow microcolony formation with the release of high numbers of planktonic cells. At the same time, genetic and phenotypic variants are formed in the dispersal population as well as in the biofilm biomass. B. When the biofilm reaches high densities, the interior of the micrcolonies become depleted in oxygen, which initiates anaerobic metabolism leading to the increased expression of nitric oxide synthetase (NirS) with the associated production of the signal molecule NO. The accumulation of NO ultimately leads to a reduction in the concentration of the intracellular signal, c-di-GMP through the action of phosphodiesterase activity (EAL domains), inducing dispersal. C. The dispersal population, comprised of wild-type cells and variants, seek out and colonize new sites, where colonization results in the establishment of either multivariant biofilms, mono-variant biofilms, or biofilms consisting of the wild-type only. D. The development of biofilms with genetic variants, either by diversification with the mature biofilm (as in A) or through the establishment of new biofilms (as in C), has fitness consequences for the population when faced with ecologically relevant pressures, such as predation by protozoa. 


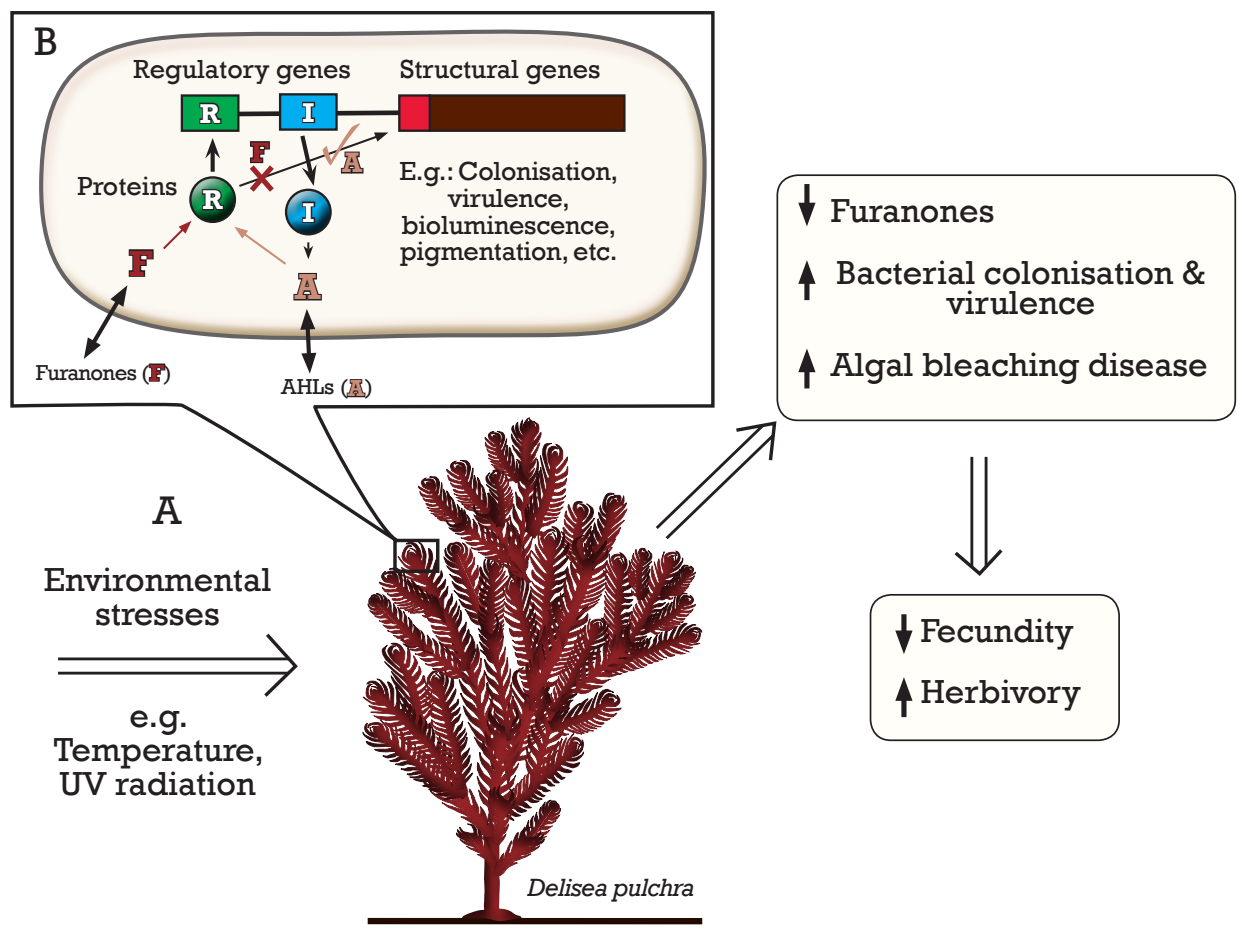




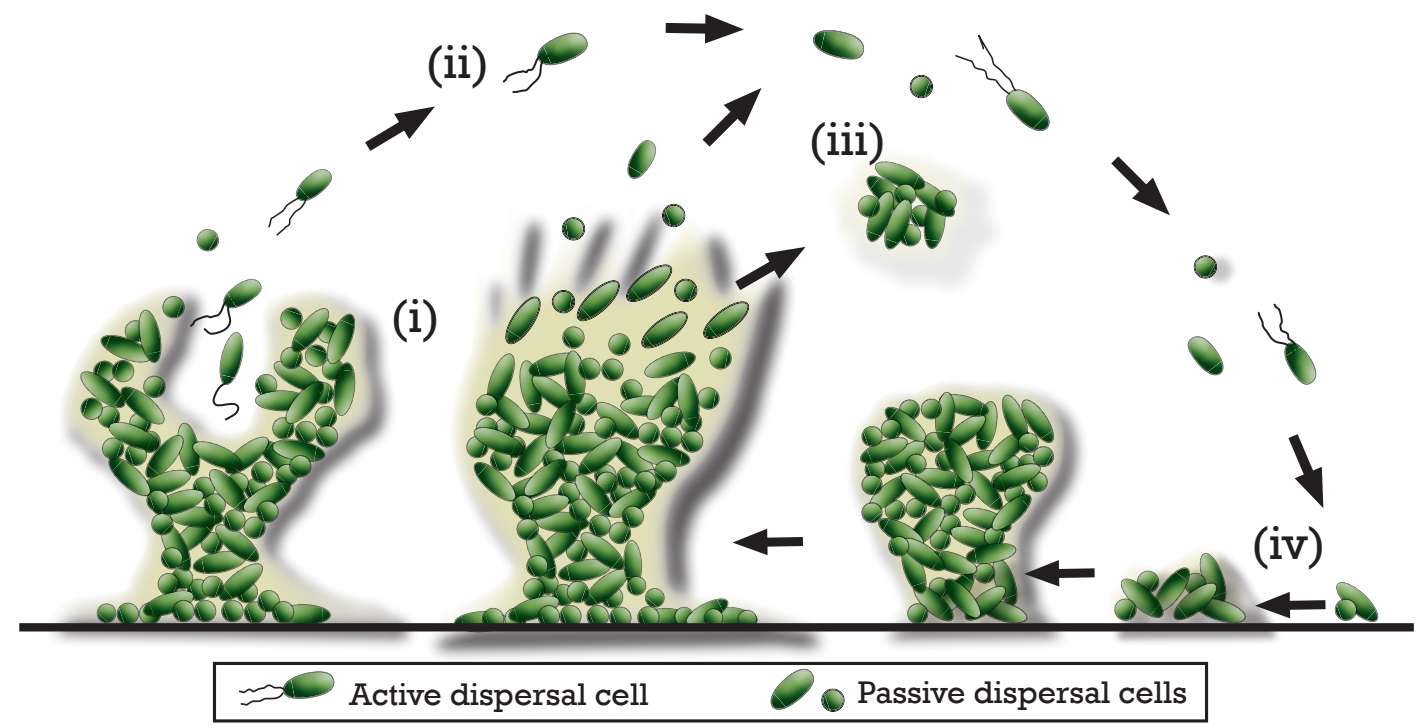




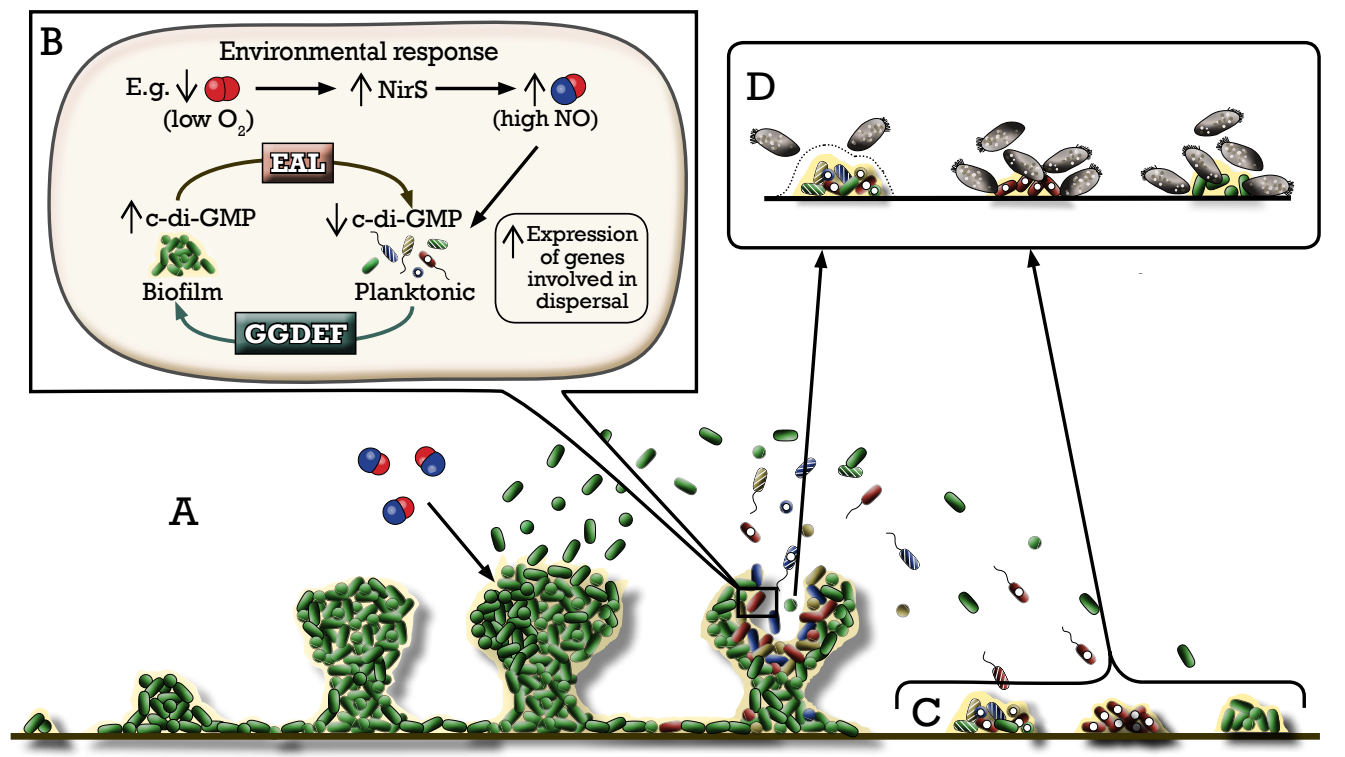

$\begin{array}{lll}\text { D Molecular oxygen } & \text { Wild type cells } \\ \text { Nitric oxide } & \text { Protozoan }\end{array}$ 